\title{
SPINOZA'S METHOD
}

\author{
Donald Mangum
}

The primary aim of this paper will be to provide the reader of Spinoza with a certain approach to the Ethics. The approach is designed to prevent what I believe to be certain natural misconceptions concerning the presuppositions behind the text. In general these presuppositions have to do with method. Spinoza begins, first, by giving us definitions of things; e.g., God, Substance, etc.; second, by giving us axioms about the natures of things, and then proceeds to deduce, in natures of things. How are we to read such a method? A natural approach to any method of discovery about things, as this one seens to be, is to read through the method into the subject matter itself. For inotance, if one points to the moon and says, "Look there," we do not look at his finger; we look beyond it to the moon itself. Here the method is transparent; we look through it, not as intrinsically an object of concern, but as an object of concern, nevertheless. But what of such a method's employment in an ethical inquiry? Assuming that one's ethical interests are in the structuring of one's conduct or behavior-$i$.e. in what one should do with oneself--the case seems no different. Geometry 1 tself is often employed in determining how one should do certain things. For example, the architect employs the geometric order to discover the laws of the triangle: Those laws then prescribe the manner in which he is to build, say, a bridge. The method of proof is important to the architect only to the extent that it reveals for him those properties of the triangle which prescribe the manner in which to build a bridge. Method is not, here, intrinsically, the object of concern, but is, rather, a mediator or vehicle rendering Being ascessible to an interested party. What j.s interesting to note, here, is the passive relationship which the architect has with the triangle he discovers. Such is the consequence of the prescriptive nature of the triangle with respect to the architect's interests--a seemingly natural approach. But as natural as these approaches may be to the methodological order of the Ethics, they are, as I will soon show, harmful to a proper under-
standing of the work. 
What one needs to know to prepare for'Spinoza's method is to be found in the treatise, On the Improvement of the Understanding. In this paper I wi 11 investigate some of the presuppositions that lie behind Spinoza's method. As it turns out, method is, for Spinoza, not a means for discovery, which means is to be read through. Method is a construction out of it self. It is a process of mental growth or development. It is, itself, the object of intrinsic concern.

But before the direct consideration of any method, it is first necessary to determine precisely what it is that the method is intended to accomplish. In the first paragraph in on the Improvement of the Understanding, we read,

After experience had taught me that all the usual surroundings of social life are vain and futile; seeing that none of the objects of my fears contained in themselves anything either good or bad, except in so far as the mind is affected by them, I finally resolved to inquire whether there might be some real good having power to communicate itself, which would affect the mind singly, to the exclusion of all else: whether, in fact, there might be anything of which the discovery and attainment would enable me to enjoy continuous, supreme, and unending happiness. 1

It is a large order, but it is a clear one. We seek an affection of the mind whereby to be as happy as possible. If we read this passage carefully we get a foreshadowing of much of the flavor and tone of the Ethics already. If what we seek is neither good nor bad except in so far as the mind is affected by it, then we may certainly anticipate a subjectivistic outcome in the Ethics itself. Whatever the method, it must be designed to effect a certain state of mind. Later, Spinoza is more specific in telling us what sort of affection of the mind this is to be. It is,"...the knowledge of the union existing between the mind and the whole of $\mathrm{Na}$ ture." 2 Just how such knowledge can be the highest good for man, we, of course, do not yet see. It is enough, however, to understand that what the method is to accomplish is to attain to a certain knowledge. Spinoza also specifies that this is to be knowledge of a certain kind; namely, "...the perception arising when a thing is perceived soleiy through its essence, or through the knowledge of its proximate cause." 3 "The method for attaining knowledge of the specified type must, therefore, consist, as least partially, in aquiring knowledge of essences and/or proximate causes. 
Having thus examined some of Spinoza's presuppositions concerning what is to be accomplished in an ethical inquiry, we may now consider more directly his choice of method.

In discussing what method is to be employed, Spinoza warns against involving oneself in an infinite regress: "...that is, in order to discover the best method for finding out the truth, there is no need of another method to discover such method; nor of a third method for discovering the second, and so on to infinity." 4 What this means is that in choosing the proper method, we must avoid the approach which asks, How do we know that we know a thing?, for we are then forced into the question, How do we know that we know that we know a thing?, and so on ad infinitum. The problem, however, is that the question, How do we know that we know a thing?, seems to be a perfectly valid question. Moreover, it is a question which some philosophers, as we shall soon see, are obliged, by the nature of their claims to knowledge, to answer. Spinoza, on the other hand, disclaims any such obligation. The fact that Spinoza denies this obligation is perhaps the most significant aspect of his method. He denies it for two reasons, both of which, taken together reveal not only the most basic ideas behind the method itself, but also a major portion of the theme of the Ethics as a whole.

The first reason is given in the form of an analogy. In order to construct a mechanism, it is first necessary to have at one's disposal certain tools. In order to construct these tools, it is, in turn, necessary to have certain other tools. But there were obviously some primitive first tools with which to start the chain of construction, for otherwise there would be no complex mechanisms which there obviously are. Even if there were an infinite regress of the tools required to make more complex tools, it would be absurd to argue on the basis of this infinite regress that the re are no mechanisms or tools, for there obviously are. Likewise, in the case of knowledge and the method for aquiring it, a complex idea requires, for its construction, simpler ideas. For example, we cannot form the idea of a circle unless we already have the ideas of a line and of the possibility of rotating that line with one point fixed. We cannot, in turn, have the idea of a line unless we already have the simpler ideas of two points. But though we may well ask of certain complex ideas how they were acquired, it would be absurd to claim that an infinite regress of simpler ideas contradicts the possibility of an idea of a circle, for we obviously have such an idea. The point is not that the question, How is knowledge possible?, is not a valid question; it is simply that 
one is not obliged to answer it in order to lay claim to knowledge.

Now if we examine the analogy of the tools more closely, we notice a rather peculiar assumption that Spinoza is making about knowledge. The analogy holds only for the aquiring of knowledge as entirely an active affair. Ideas are, here, constructions by the mind rather than innate, pre-established entities or passive receptions from the world. Needless to say, such an assumption would require a rather explicit theory of knowledge in order to be valid. Spinoza does offer such a theory; namely, the theory of knowledge as subjective essence. He relies even more heavily on this theory in his second reason for denying the obligation to answer the question of how we know that we know. Briefly, the theory portrays knowledge as an independent power of the mind--independent, that is, from both its objective correlate and any higher method of verification. But be fore going further into this theory, it will be useful, first, to see how it works for Spinoza in avoiding the infinite regress of methods.

The second reason for dismissing the question of how we know that we know consists in the fact that knowledge as the subjective essence of the thing known, and as, therefore, an actuality in and of itself, does not depend, for its existence, on the knowledge of it. For example, the idea of a circle is not itself circular. It is therefore something different from the circle itself; namely, the subjective essence of the circle. The idea of the circle also allows of being the object of another idea, which is precisely the case when we ask of the idea of a circle how such an idea is possible. The idea of the idea of the circle is the subjective essence of the subjective essence of the circle. But by forming this second subjective essence, we by no means alter the first. In fact the second subjective essence depends on the first, which is what Spinoza means when he says that, "... in order to know that I know, I must first know." 5 The fact that we may form this second level subjective essence of the idea of the circle by asking, How is knowledge of the circle possible?, does not alter the status of the first level subjective essence; that is, it is still knowledge. Thus, in order to claim to know a thing, it is not necessary to answer the question, How do $I$ know that I know?, if I do, in fact, know.

Now the significance of these arguments lies in the fact that they simply will not work if, by knowledge, we mean a state of affection of the mind which depends, for its nature, on something other than itself. For example, 
a causal theorist of knowledge would have to justify his claim to know a thing by reference to the thing itself; that is, he would have to show that the thing of which he had the idea did in fact cause his idea. This he cannot, of course, do for in order to show that the object caused his idea, he would first have to have knowledge of the object, which is, itself, what is to be proved.6 Hence, if by "the knowledge of a circle," Spinoza meant an idea caused by some separate extended figure, then he could not point to the knowledge of the circle as proof of the fact that he has knowledge, for then he would have to show that the extended figure did in fact cause his idea, which would require that he know the extended circle, which is, itself, the thing to be proved. With regard to knowledge as the subjective essence of a thing-that is, an idea which is an actuality separate from its object, and which allows of being the object of another idea or knowledge--such a knowledge could not, by definition, be a state of mind which depends for its nature on something other than itself. This is simply what it means to say that the idea is separate from its object, or, in Spinoza's words, "... as it is something different from its correlate, it is capable of being understood through itself..."7" If knowledge were dependent for its nature on something other than itself, then we obviously could not understand it through itself alone, but only through that on which it depends for its nature.

What are we to make of these arguments? The first states, in effect, that it is absurd to question that we know, for we already have the answer; that is, we do know. The second states, in effect that it is unnecessary to question how we know as long as all we desire is that we know. I suggest that the best way to take these arguments is simply as characterizations of knowledge in Spinoza's sense. Spinoza says, immediately after giving the arguments,

Hence it is clear that certainty is nothing else than the subjective essence of a thing; in other words, the mode in which we perceive an actual reality is certainty. Further, it is also evident that, for the certitude of truth, no further sign is necessary beyond the possession of a true idea: for, as I have shown, it is not necessary to know that we know that we

True knowledge is therefore an independent power of the mind. It owes no apologies, elther to the extended world in itself or to a higher verificatory knowledge. What, then, is to be the method for aquir- 
ing knowledge of this sort? Spinoza says that method, "...is nothing else than reflective knowledge, of the idea of an idea; and .... as there can be no, idea of an idea--unless an idea exists previously--thére can be no method without a pre-existent idea."g . But the reflective knowledge of this pre-existent idea is, of course, not the whole of the method. To understand further how reflective knowledge is to count as method we may return to the analogy of the tools. We possess certain simple tools whereby to construct more complex tools, which, in turn, are used to construct stili more complex tools. We find a similar process of construction in reflective knowledge as method for aquiring more complex knowledge. For example, taking the simple idea of a point together with another simple idea of a point, we form the more complex idea of a line. Taking this idea of a line together with the idea of rotating that line, we form the idea of a circle. Again, from this idea, the ideas of an infinity of equal rectangles follow. But all these ideas are but independent powers of the mind-independent, that is, of extended lines, circles, and rectangles. They are pure constructions by the mind of complex ideas out of simple ideas. They are to be understood solely through themselves and without reference to anything beyond themselves. The certainty of these truths, i.e., the certainty of the properties of
the circle, lies wholly in the reflective activity of
the mind. It is not the assures us that we the truth of these properties that our knowledge of these properties thereof; it is, rather, truth. In Spinoza's words "thes that assures us of their an actual reality is certainty." mode in which we perceive

Let us return now to what it is that is to be accomplished by our method. It is to aquire an affection of the mind that will bring supreme and unending happiness. This affection of the mind is the knowlwhole of Nature. acquire, the meth As it is a knowledge that we wish to of simpler knowledge. attempt to discover the The Ethics is, therefore, not an the good! Any other reading; it is an attempt to create reading. This is, of course, not to book wili be a misof the mind with the whole of not to say that the union prior to the knowledge of that Nature does not exist say that such a union does not, in anion; is simply to stitute the highest good for man. the subjective essence of this . The good for man is to be understood through itse union, which essence is correlate. We have, the construction of this idea disposal, certain tools for plest of these tools are the , or knowledge. The simthe beginning of each part definitions and axioms at 
definitions and axioms we are able to construct more and more complex ideas which are the propositions of the Ethics. But though we may, to some extent, structure our Iives in accordance with some of the things that these propositions tell us--that is, though some of these propositions may take on a prescriptive character--the method is not for us prescriptive to the extent that it is for the architect.

I have, of course, not given anything like a thorough exposition or elucidation of Spinoza's method, nor have $I$ intended to. What $I$ have covered (and that only briefly) is basically the first part of Spinoza's system of choosing a method. The rest consists in actually putting this theory to work; for instance, putting ideas in the form of a definition. I think, though, that the theory itself is all that is needed in order to prevent a misreading of the text. In other words, as long as we do not attempt to read through the method, as we read through the finger to the moon, then we will be able to read the text as it was written; namely, as the activity of the mind at its fullest potential, for it is precisely that potential which constitutes the highest good for man.

Louisiana State University 
NOTES

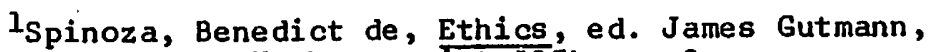
Hafner Press, New York, reprint 1974, p. 3.

2Ibid. p. 6.

3 Ibid. p. 8.

"I bid. p. 10.

5 Ibid. p. 12.

${ }^{6}$ We may recall, here, Locke, for whom our ḳnowledge of an object is through secondary qualities which are "caused by," though not identical with what inheres in the object itself. But as Hume was able to show, since our knowledge consists solely in the "effect," we can have no knowledge of a "cause"; not even the knowledge that there is a cause.

7 Ibid. p. 11 .

${ }^{8}$ Ibid. p. 12 .

9 Ibid. p. 13. 